\title{
PERANCANGAN SISTEM PENDETEKSIAN KANTONG KOSONG PADA 662-BT1 UNTUK MENGURANGI FREKUENSI BAG GAP PADA 672-PA1
}

\author{
Sonki Prasetya ${ }^{1}$, M. Nashirul Mahasin ${ }^{2}$, Hendra Susanto $^{3}$ \\ 1,2Politeknik Negeri Jakarta, Kampus Baru UI Depok, 16425. \\ ${ }^{3} \mathrm{PT}$. Holcim Indonesia Tbk. \\ e-mail : ${ }^{1}$ sonki.prasetya@mesin.pnj.ac.id
}

\begin{abstract}
A Packhouse is one of the cement packing area commonly exist in a cement plant. There are 2 primary machines used in packing cement process, namelya packer machine and a palletizer. A palletizer is an equipment for organizing the cemet bag on the pallet. The cement are organized in twotypes of pattern layer either 3\&2 or 2\&3 pattern. An alignment belt is utilized in order to set the position of bag based of the pattern. Furthermore, the timing belt provides a function to ensure gap between cement more than 100mm. If the gap is not achieved, the palletizer will be switched off the automation system, and show the bag gap notification. In december, it was recorded 365 times of palletizer automation failure caused by bag gap alarm. Therefore, there are 22.995 product loses. Most of bag gap problem is caused by an empty bag. The position of the failed product (empty cement bag)stick with the cement product.To prevent the empty bag enters the palletizer system by evacuating it pass through the belt trap, an additional photocell sensor can be added. It has the function to detect lenght of cement bag and gives an input to controller (PLC). The PLC process the input based on the time interval detection.The sistem will active if the set point in its program is reached.Thetrigger sensor detects the failed product.Furthermore, 662-BT1 will reject the cement bag.The aim of this study is design the system to deccrease the frequency of system failure caused by failed cement bag that enters the palletizer system. This willhelp the system when the problem rises.Implementation of this system decreases the bag gap alarm caused by the empty bag. Thus, the performance of palletizer will increase.
\end{abstract}

Key words :bag gap, PLC,overlap, belt trap.

\begin{abstract}
ABSTRAK
Packhouse adalah area packing semen yang terdapat pada setiap pabrik semen. Terdapat dua alat utama yang digunakan dalam proses packing semen yaitu: Packer Machine dan Palletizer. Palletizer adalah alat yang digunakan untuk menata semen di atas pallet. Semen tersebut terdiri dari 2 pattern layer yaitu: pattern 32 dan pattern 2 3.Posisi semen diatur pada alignment belt, alignment belt mendapat umpan semen dari Timing Belt, timing belt berfungsi memastikan jarak antar semen yang diumpan tidak kurang dari $100 \mathrm{~mm}$. Jika jarak antar semen tidak tercapai maka palletizer akan mematikan sistem otomatisasinya, dan akan menampilkan alarm bag gap. Pada bulan desember 365 kali kegagalan sistem otomatisasi palletizer disebabkan oleh alarm bag gap dan menyebabkan loses sejumlah 22.995 produk. Salah satu penyebab bag gap adalah adanya kantong semen kosong yang terevakuasi oleh packer machine dan terbaca oleh sensor pada palletizer yang berfungsi untuk mendeteksi jarak antar kantong semen. Posisi kantong semen kosong tersebut overlap dengan kantong semen.Pencegahan kantong kosong masuk kedalam sistem palletizer yaitu mengeluarkannya dari sistem transport melalui belt trap, dengan cara menambahkan sensor photocell dan program pada PLC. Sensor photocell berfungsi mendeteksi panjang semen dan memberi inputan pada PLC, PLC mengolah inputan berdasarkan lama waktu pendeteksian kantong semen, jika setpoint tercapai dan produk terdeteksi sensor trigger maka 662-BT1 akan bekerja untuk mengeluarkan produk dari transport. Tujuan dari studi ini adalah merancang sistem untuk mengurangi frekuensi kegagalan pada sistem yang sudah ada akibat adanya kantong semen kosong yang masuk kedalam sistem palletizer dan mempermudah proses penanganan. Setelah penerapan sistem ini aktifnya alarm bag gap akibat adanya bag kosong dapat berkurang dan produktifitas palletizer dapat meningkat.
\end{abstract}

Kata kunci :bag gap, PLC,overlap, belt trap. 


\section{PENDAHULUAN}

PT. Holcim Indonesia adalah perusaan yang bergerak dalam industri semen, secara umum produk semen dijual dalam 3 bentuk yaitu: semen bulk, semen kantong dan klinker.Area produksi semen kantong disebut area packhouse, ada 2 alat utama dalam proses packing yaitu: packer machine yang berfungsi sebagai pengisi semen bulk kedalam kantong semen dan palletizer yang berfungsi sebagai penata semen kantong diatas pallet.

Saat proses produksi pada mesin packer semen kantong yang telah memiliki bobot sesuai akan di evakuasi ke belt evacuation. Pada beberapa kasus terdapat kantong kosong yang terselip di bawah semen kantong ikut terevakuasi, kantong kosong tersebut terselip pada dudukan bag akibat adanya miss shoting pada saat proses pengumpanan bag ke mesin packer, pada putaran selanjutnya sistem packer mendeteksi tidak ada kantong semen sehingga akan diumpan kembali, jika pengumpanan kedua ini tepat maka semen kantong ini akan diisi oleh mesin packer dan setelah bobot sesuai maka semen kantong akan dievakuasi beserta dengan kantong kosong yang terselip. Jika posisi kantong kosong tersebut overlap maka sensor bag gap pada belt weigher tidak dapat mendeteksi, dan saat kantong kosong tersebut memasuki palletizer, sensor bag gap pada palletizer mendeteksi adanya jarak gap antar semen yang kurang dari jarak yang dipersyaratkan, sehingga akan muncul alarm bag gap dan mesin palletizer akan berhenti. Terlebih jika sensor bag gap tidak dapat mendeteksi maka kantong kosong tersebut akan dideteksi oleh sistem sebagai semen kantong, apabila operator mesin tidak menayadari hal tersebut maka kantong kosong akan masuk kedalam susunan layer pada pallet dan dapat mengakibatkan robohnya susunan pallet. Hal ini sangat mempengaruhi kinerja palletizer. Ada beberapa posisi kantong kosong yang terevakuasi, salah satunya yaitu overlap dengan semen kantong, seperti pada Gambar 1. Tidak adanya sistem yang mendeteksi kantong kosong tersebut dapat menimbulkan kerugian diantaranya banyaknya alarm bag gap yang mematikan sistem palletizer, sebanyak 365 alarm pada bulan desember terjadi akibat bag gap. Rata-rata waktu mesin mati akibat alarm ini sebesar 1 menit[1]. Jika dalam satu menit mesin dapat menghasilkan 63 produk semen kantong, maka kerugian yang diakibatkan oleh alarm bag gap ini sebesar 22.995 produk semen kantong.

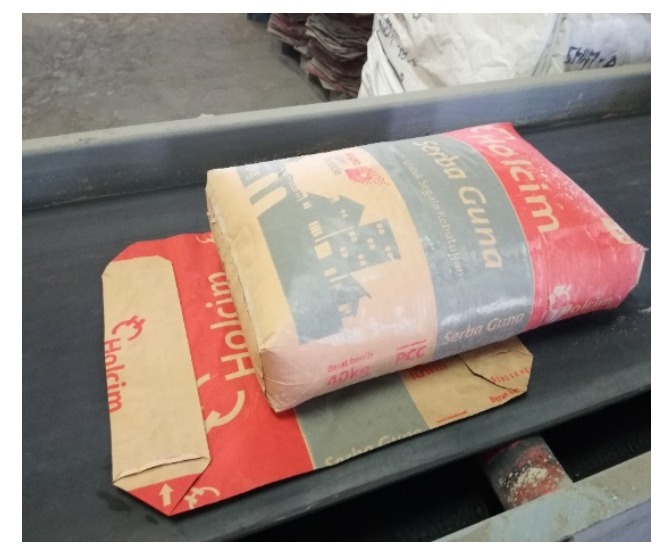

Gambar 1. Posisi kantong kosong saat terevakuasi

Oleh sebab itu diperlukan investasi untuk sistem pendeteksi kantong kosong untuk mencegahnya memasuki sistem palletizer.

Perancangan sistem pendeteksian yang dapat mengevakuasi kantong kosong secara otomatis dapat meminimalkan jumlah alarm bag gap.

Adapun tujuan dari perancangan sistem pendeteksian kantong kosong iniantara lain menemukan solusi dari masalah bag gap pada palletizer tanpa banyak merubah system yang sudah ada, menurunkan jumlah terjadinya masalah(system failure) akibat bag kosong, membantu mempermudah proses pengendalian system dengan otomasi problem yang dialami. 


\section{METODE PENELITIAN}

Metode penelitian yang digunakan, digambarkan dengan diagram alir seperti pada Gambar 2 di bawah ini.
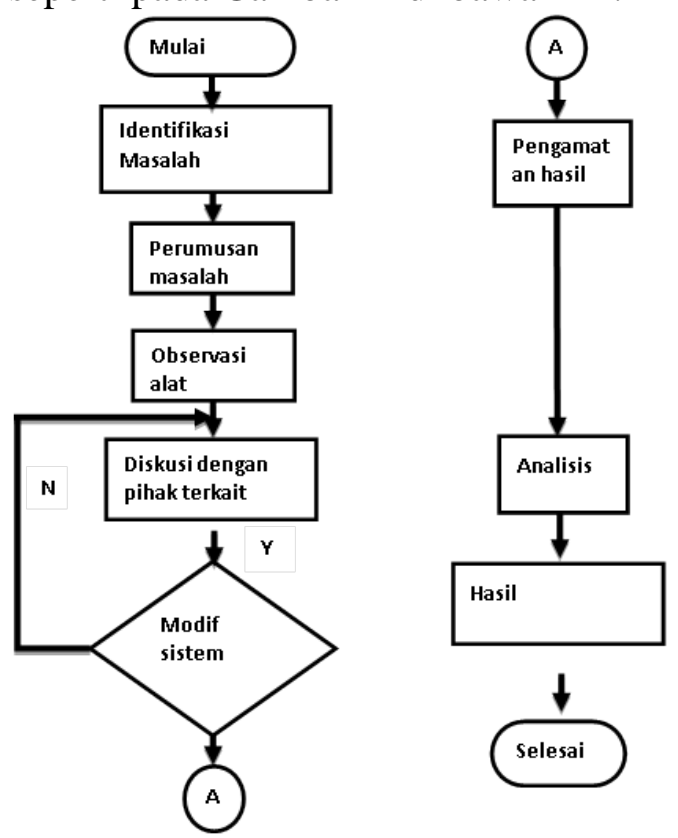

Gambar 2. Diagram alir metode penelitian

Pada tahap pertama dilakukan identifikasi masalah dilakukan untuk mengetahui latar awal masalah yang menyebabkan bag gap alarm. Mengamati apa penyebab utama dari munculnya alarm ini.

Perumusan masalah ditentukan setelah masalah teridentifikasi. Rincian masalah diperlukan untuk mengetahui pokok masalah. Tujuan penelitian ini yaitu untuk mencegah adanya kantong kosong yang terevakuasi tidak menganggu dalam proses palletizer.

Observasi alat serta diskusi dengan pembimbing lapangan untuk mencari solusi penanganan kantong kosong, serta mencari letak sistem modifikasi, serta pemilihan sensor yang akan digunakan dalam sistem tersebut dan pemasangan sensor yang paling efektif untuk diterapkan. Pada tahap ini juga dilakukan pemilihan tipe sensor yang akan dipakai dan posisi pemasangan sensor.

\section{HASIL dan PEMBAHASAN}

Berdasarkan hasil observasi yang dilakukan selama masa spesialisasi di
Departemen Production Finish Mill and Dispatch PT.Holcim Indonesia Tbk. Pabrik Tuban. Ditemukan banyaknya alarm bag gap yang diakibatkan oleh adanya kantong kosong yang terevakasi dan masuk ke palletizer, hal ini mempengaruhi produktifitas palletizer. Oleh karena itu modifikasi sistem yang dapat mendeteksi adanya kantong kosong serta dapat mengevakuasinya dari sistem transport untuk meminimalisir alarm bag gap pada palletizer. Dari hasil diskusi dengan pihak terkait didapatkan rancangan modifikasi untuk penambahan input 662-BT1, setiap semen kantong yang dideteksi adanya kantong kosong maka sistem PLC akan mengeluarkannya dari transport melalui 662-BT1. Dikarenakan posisi kantong kosong yang overlap seperti pada Gambar.1 dan Gambar.3maka proses identifikasi adanya kantong kosong dilakukan dengan cara pengukuran panjang oleh sensor, jika sensor mendeteksi panjang semen lebih dari $600 \mathrm{~mm}(40 \mathrm{~kg})$ atau 742 mm (50 kg) maka sistem PLC akan mendeteksi adanya kantong kosong yang overlap dan akan mengeluarkannya dari transport melalui 662-BT1. Selain itu posisi pemasangan sensor juga harus dipertimbangkan, hal ini agar sensor dapat membaca kantong kosong pada semua posisi.

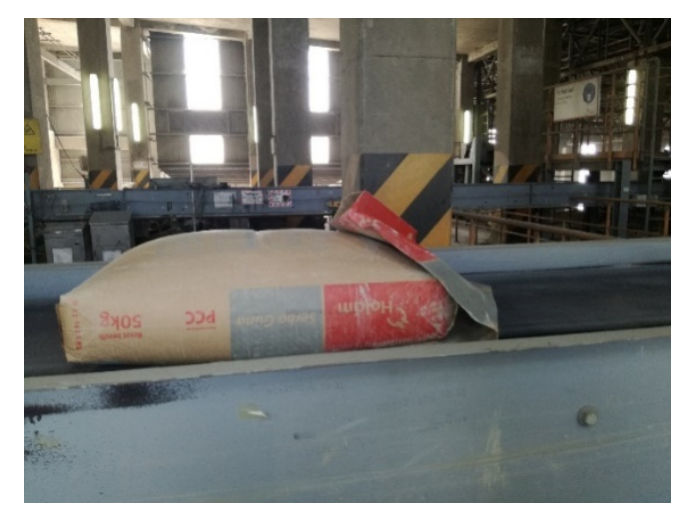

Gambar 3. Posisi kantong kosong yang tumpang dengan semen kantong

Berdasarkan pertimbangan kelebihan dan kekurangan sensor seperti pada 
Tabel.1, maka dipilih penggunaan photocell sensor tipe diffusereflective.

\section{Diffuse}

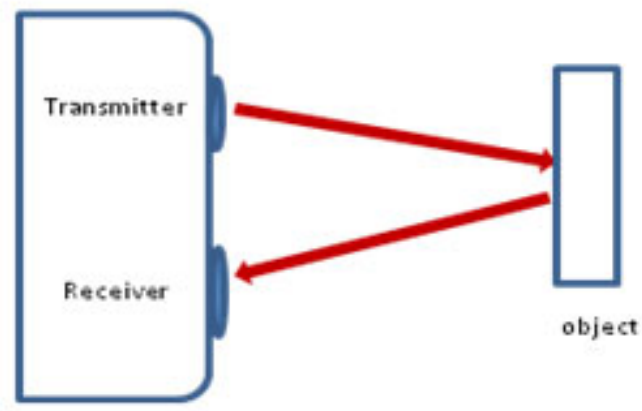

Gambar 4. Prinsip kerja diffuse reflective sensor[2].

Konsep pertama menggunakan sensor cahaya tipe Diffuse-reflective Sensors.Sensor jenis ini memiliki desain yang sangat sederhana dimana receiver dan transmitter terkombinasi pada satu alat,sehingga tidak memerlukan reflector khusus, seperti pada Gambar.4 sinar yang di pancarkan oleh transmitter dipantulkan oleh benda (objek sensing) itu sendiri [3].

Berikut kelebihan dan kekurangan sensor tipe ini [4]:

$>$ Kelebihan

- Pemasangan mudah.

- Hanya membutuhkan 1 titik pemasangan. (Tidak membutuhkan reflector)

- Proses adjustable mudah

- Dapat mendeteksi benda yang memiliki permukaan tidak rata.

- Perawatan mudah.

$>$ Kekurangan

- $\quad$ Range sensing terbatas.

- Range sensing berdasarkan kontras warna pada permukaan object sensing.

Berikut hasil perbandingan beberapa tipe sensor yang disesuaikan dengan indikator kebutuhan konsumen

- Sistem yang dapat bekerja pada lingkungan berdebu bersertifikasi IP 67.

- Perawatan yang mudah
- Kemudahan adjustment.

- Tingkat akurasi yang tinggi.

- Harga komponen.

Tabel 1. Pembobotan pemilihan tipe sensor

\begin{tabular}{|c|c|c|c|c|c|c|c|c|}
\hline \multirow{3}{*}{ No } & \multirow{3}{*}{ Aspek Penilaian } & \multirow{3}{*}{$\begin{array}{l}\text { Bobot } \\
(\%)\end{array}$} & \multicolumn{6}{|c|}{ Sensor } \\
\hline & & & \multicolumn{2}{|c|}{$\begin{array}{c}\text { Diffuse } \\
\text { reflective }\end{array}$} & \multicolumn{2}{|c|}{ Through beam } & \multicolumn{2}{|c|}{ Retro reflective } \\
\hline & & & $\begin{array}{l}\text { Nilai } \\
(1-5)\end{array}$ & $\begin{array}{c}\text { Nilai x } \\
\text { Bobot } \\
\text { (\%) }\end{array}$ & $\begin{array}{l}\text { Nilai } \\
(1-5)\end{array}$ & $\begin{array}{c}\text { Nilaix } \\
\text { Bobot } \\
(\%)\end{array}$ & $\begin{array}{l}\text { Nilai } \\
(1-5)\end{array}$ & \begin{tabular}{|c|} 
Nilai x \\
Bobot \\
$(\%)$ \\
\end{tabular} \\
\hline 1 & $\begin{array}{c}\text { Alat dapat bekerja } \\
\text { pada lingkungan } \\
\text { berdebu }\end{array}$ & 30 & 5 & 30 & 5 & 30 & 5 & 30 \\
\hline 2 & $\begin{array}{l}\text { Perawatan yang } \\
\text { mudah }\end{array}$ & 20 & 4 & 16 & 3 & 12 & 2 & 8 \\
\hline 3 & $\begin{array}{c}\text { Kemudahan } \\
\text { adjusment }\end{array}$ & 20 & 4 & 16 & 2 & 8 & 3 & 12 \\
\hline 4 & Tingkat akurasi & 20 & 4 & 16 & 4 & 16 & 4 & 16 \\
\hline 5 & $\begin{array}{c}\text { Harga setiap } \\
\text { komponen alat } \\
\text { dapat dijangkau }\end{array}$ & 10 & 2 & 4 & 3 & 6 & 4 & 8 \\
\hline & Total Nilai & 100 & & 82 & & 72 & & 74 \\
\hline & 1 : Very Bad & $2: \mathrm{Bad}$ & & : Medium & & 4: Good & & Very Good \\
\hline
\end{tabular}

\section{Pemilihan konsep desain berdasarkan posisi}

Pemilihan posisi memliki peranan penting dalam proses desain, agar proses sensing memiliki akurasi yang tinggi serta meminimalisir disturbance juga kemudahan dalam monitor perawatan. Berdasarkan pertimbangan kelebihan dan kekurangan dari Tabel 2, maka dipilih konsep desain posisi vertikal. Pada posisi ini sensor diletakkan di atas belt weight, seperti pada Gambar.5 garis merah merupakan ilustrasi arah sensing yang ditujukan pada celah antara 662-BW1 dan 662BC2.

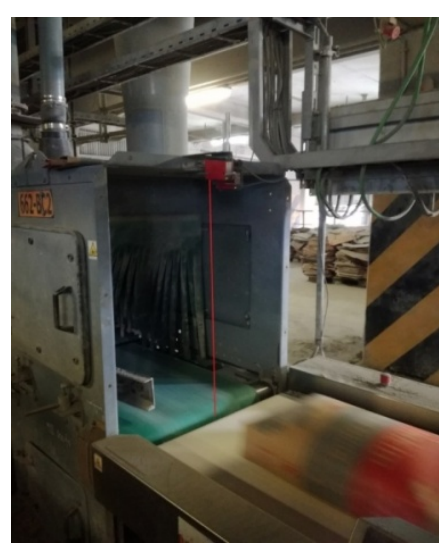

Gambar 5. Konsep desain posisi vertikal 
Berikut beberapa kelebihan dan kekurangan pada konsep desain posisi vertikal :

Kelebihan :

- Sensor terhindar dari benturan semen kantong.

- Proses adjustment yang mudah

- Paparan debu yang sedikit

- Dapat mendeteksi kantong kosong yang flat.

Kekurangan :

- Jika tumpukan pada celah masuk dalam range jarak sensing maka sensor akan terganggu.

Pada konsep desain vertikal ini sensor dapat mendeteksi kantong kosong seperti pada gambar Gambar.1dan Gambar 3.

Pada Tabel 2 dipaparkan hasil perbandingan beberapa desain posisi sensor yang disesuaikan dengan indikator kebutuhan konsumen

- Alat dapat terlindung dari paparan debu

- Monitoring yang mudah

- Kemudahan adjusment

- Akurasi pendeteksian bag

Tabel 2. Pembobotan pemilihan posisi sensor

\begin{tabular}{|c|c|c|c|c|c|c|}
\hline \multirow[b]{3}{*}{ No } & \multirow[b]{3}{*}{ Aspek Penilaian } & \multirow{3}{*}{$\begin{array}{l}\text { Bobot } \\
\text { (\%) }\end{array}$} & \multicolumn{4}{|c|}{ Konsep desain posisi } \\
\hline & & & \multicolumn{2}{|c|}{ Vertikal } & \multicolumn{2}{|c|}{ Horizontal } \\
\hline & & & $\begin{array}{l}\text { Nilai } \\
(1-5)\end{array}$ & $\begin{array}{l}\text { Nilai x } \\
\text { Bobot } \\
(\%)\end{array}$ & $\begin{array}{l}\text { Nilai } \\
(1-5)\end{array}$ & $\begin{array}{l}\text { Nilai x } \\
\text { Bobot } \\
(\%)\end{array}$ \\
\hline 1 & $\begin{array}{l}\text { Alat dapat terlindung } \\
\text { dari paparan debu }\end{array}$ & 25 & 4 & 20 & 3 & 15 \\
\hline 2 & $\begin{array}{l}\text { Monitoring yang } \\
\text { mudah }\end{array}$ & 15 & 4 & 12 & 4 & 12 \\
\hline 3 & $\begin{array}{l}\text { Kemudahan } \\
\text { adjusment }\end{array}$ & 20 & 4 & 16 & 3 & 12 \\
\hline 4 & $\begin{array}{l}\text { Sensor terlindung } \\
\text { dari benturan. }\end{array}$ & 15 & 5 & 15 & 5 & 15 \\
\hline 5 & $\begin{array}{l}\text { Akurasi pendeteksian } \\
\text { bag }\end{array}$ & 25 & 4 & 20 & 3 & 15 \\
\hline \multicolumn{2}{|c|}{ Total Nilai } & 100 & & 83 & & 69 \\
\hline
\end{tabular}

\section{Prinsip kerja alat}

Tahapan pertama dalam perancangan alat adalah pembuatan prinsip kerja. Prinsip kerja sistem pendeteksian kantong kosong ditunjukkan pada diagram blog Gambar 6 .

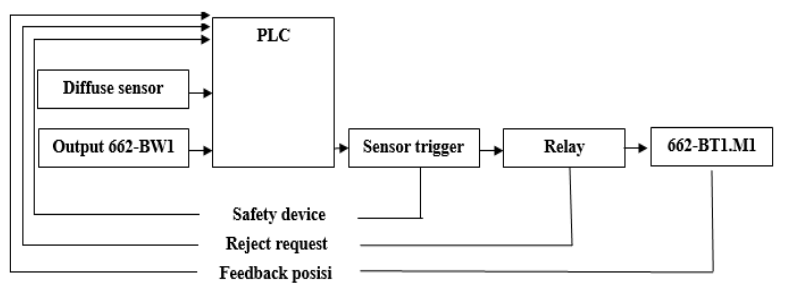

Gambar 6. Blok sistem pengendalian

Sistem alat ini menggunakan programmable logic controller (PLC) sebagai pengendali utamanya. Sistim ini interlock denga belt weight, jadi ketika belt weight beroperasi maka sistem akan secara otomatis on. Jika ada semen kantong yeng terbaca oleh diffuse sensor maka sensor akan memberi sinyal 1 pada input PLC, kemudian PLC akan mengukur lama waktu pembacaan sensor, jika lama waktu pembacaan sensor mencapai setpoint maka PLC akan mengeluarkan output 1 , setelah sensor trigger memberi inputan 1 maka relay akan aktif kemudian relay akan mengaktifkan 662-BT1.M1 untuk on pada posisi buka. Selain itu relay juga memberikan feedback untuk PLC, hal ini berfungsi untuk memberikan inputstart pada timer, setelah timer tercapai maka sistem akan reset dan relay akan mati untuk memerintahkan 662-BT1.M1 pada posisi menutup (transport) . pada sensor triggerselain sebagai switch relay juga sebagai safety device, jika waktu buka belum tercapai tetapi sensor trigger bekerja maka relay akan off.

\section{Penentuan parameter kerja}

Dalam proses otomasi suatu alat harus bekerja sesuai deskripsi kerja (squence), oleh karena itu program yang digunakan untuk menjalankannya membutuhkan set point (parameter) agar sistem automasi dapat mengenali waktu mulai dan berhentinya proses.

a. Perhitungan set point timer[5].

Perhitungan waktu sensing semen 40 kg. 


$$
\begin{aligned}
v & =\frac{s}{t} \\
t & =\frac{s}{v}
\end{aligned}
$$

$$
\begin{aligned}
& \text { Keterangan : } \\
& \mathrm{v} \quad=\operatorname{kecepatan}(\mathrm{m} / \mathrm{s}) \\
& \mathrm{s} \quad=\text { jarak }(\mathrm{m}) \\
& \mathrm{t}=\text { waktu }
\end{aligned}
$$

$\mathrm{v}=$ kecepatan belt weigher adalah 1,35 $\mathrm{m} / \mathrm{s}$

$\mathrm{s}=$ panjang semen kantong adalah 600 $\mathrm{mm}=0,6 \mathrm{~m}$

$$
\begin{aligned}
& t=\frac{s}{v} \\
& t=\frac{0,6 m}{1,35 m / s} \\
& \mathrm{t}=0,444 \mathrm{~s} \\
& \mathrm{t}=444 \mathrm{~ms} \text {. }
\end{aligned}
$$

Perhitungan waktu sensing semen 50 kg.

$$
\begin{aligned}
& \mathrm{v}=1,35 \mathrm{~m} / \mathrm{s} \\
& \mathrm{s}=0,742 \mathrm{~m} \\
& \boldsymbol{t}=\frac{\boldsymbol{s}}{v} \ldots \ldots \ldots \ldots \ldots \ldots \ldots \ldots \ldots \\
& \boldsymbol{t}=\frac{\mathbf{0 , 7 4 2 m}}{\mathbf{1 , 3 5 ~} \mathbf{m} / \mathbf{s}} \\
& \mathbf{t}=\mathbf{0 , 5 4 9} \mathbf{s} \\
& \mathbf{t}=\mathbf{5 4 9} \mathbf{~ m s} .
\end{aligned}
$$

\section{Desain Instrumentasi}

Pada Gambar 6 terdapat dua mode utama yaitu mode produk $40 \mathrm{~kg}$ untuk pendeteksian kantong kosong saat produksi semen $40 \mathrm{~kg}$. dan mode produk $50 \mathrm{~kg}$ untuk pendeteksian kantong kosong saat produksi semen $50 \mathrm{~kg}$. Terdapat 3 sensor dalam rangaian ini, pertama sensor diffuse (bag gap sensor) yang berfungsi sebagai sebagai pendeteksi panjang semen kantong, kedua through beam sensor yang berfungsi sebagai reject trigger dan ketiga proximity sensor sebagai indikasi 662.BT1 dalam kondisi terbuka (mereject semen kantong)

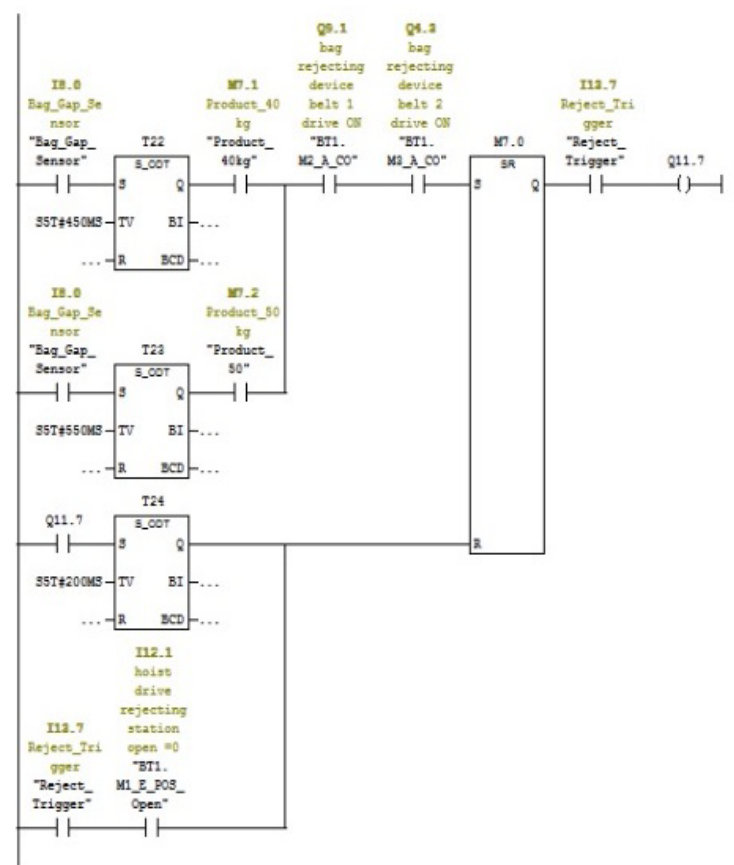

Gambar 6. Program dengan ladder diagram PLC

Syarat sistem pada Gambar.6 dapat bekerja:

1. Jenis produk yang di produksi terpenuhi.

2. BT1.M2 dan BT1.M3 dalam kondisi running

3. BT1 .M1 dalam kondisi transport (M7.0 dalam kondisi reset).

4. Timer T22 aktif (adanya kantong kosong pada semen kantong).

Berikut alur kerja dari Gambar.6 diatas :

1. Bag gap sensor mendeteksi ukuran semen kantong.

2. Input waktu sensing melebihi set point.

3. T22 akan aktif dan memberikan inputan pada M7.0

4. M7.0 dalam kondisi set

5. Sensor reject trigger akan mendeteksi adanya bag

6. Q11.7 aktif (662.BT1 membuka) dan memberikan input pada port set T24

7. Setelah 200 ms T24 akan aktif dan memberikan inputan pada port reset M7.0

8. 662.BT1 akan kembali pada posisi transport (menutup) 
Note : jika Sensor reject trigger mendeteksi kantong semen setelahnya maka langkah ke 6 dan ke 7 akan di bypass.

\section{KESIMPULAN}

Dari penelitian ini didapatkan kesimpulan bahwa solusi untuk mendeteksi problem di palletizer ini menggunakan tipe diffuse sensor dengan pemasangan secara vertikal. Alat dapat dioperasikan dalam dua mode baik mode $40 \mathrm{~kg}$ maupunmode 50 kg sesuai dengan kondisi yang sudah ada. Perancangan sistem ini sebagai bentuk pencegahan kantong kosong memasuki palletizer dengan cara mengeluarkannya melalui 662-BT1, karenanya frekuensi alarm bag gap dapat dikurangi. Adanya sistem deteksi kantong kosong ini dapat mempermudah proses pengendalian karena sistem ini dapat mendeteksi kantong kosong serta mengevakuasi secara otomatis (yang sebelumnya manual), sehingga tidak dibutuhkan tenaga manual untuk mengevakuasinya, dan tidak perlu mematikan mesin.

\section{UCAPAN TERIMAKASIH}

Bapak Andri Iswanto, karyawan dan kontraktor PT. Holcim Indonesia Tbk Pabrik Tuban atas kerja samanya di kegiatan ini.

\section{DAFTAR PUSTAKA}

[1] T. P. PT HOLCIM INDONESIA Tbk,2017, "alarm bag gap desember".

[2] Photoelectric Sensors - The 3 basic Modes of operation. Available: https://uk.rs-online.com

[3] D. S. Solomon, 1998 "SENSORS HANDBOOK," p. 2.7.

[4] D. S. Solomon, 1998, "SENSORS HANDBOOK," p. 2.8.

[5] M. H. U. Fischer, F. Naher, and Paetzold, 2006, "Mechanical and
Metal Trade Handbook," VERLAG EUROPA LEHRMITTEL, vol. 1, p. 34. 
Sonki Prasetya, M Nashirul Mahasin, Hendra Susanto,Pendeteksian Kantong Semen... 